\title{
Early Activation of Ventral Hippocampus and Subiculum during Spontaneous Seizures in a Rat Model of Temporal Lobe Epilepsy
}

\author{
Izumi Toyoda, ${ }^{1}$ Mark R. Bower, ${ }^{1}$ Fernando Leyva, ${ }^{1}$ and Paul S. Buckmaster ${ }^{1,2}$ \\ ${ }^{1}$ Department of Comparative Medicine and ${ }^{2}$ Department of Neurology and Neurological Sciences, Stanford University, Stanford, California 94305
}

Temporal lobe epilepsy is the most common form of epilepsy in adults. The pilocarpine-treated rat model is used frequently to investigate temporal lobe epilepsy. The validity of the pilocarpine model has been challenged based largely on concerns that seizures might initiate in different brain regions in rats than in patients. The present study used 32 recording electrodes per rat to evaluate spontaneous seizures in various brain regions including the septum, dorsomedial thalamus, amygdala, olfactory cortex, dorsal and ventral hippocampus, substantia nigra, entorhinal cortex, and ventral subiculum. Compared with published results from patients, seizures in rats tended to be shorter, spread faster and more extensively, generate behavioral manifestations more quickly, and produce generalized convulsions more frequently. Similarities to patients included electrographic waveform patterns at seizure onset, variability in sites of earliest seizure activity within individuals, and variability in patterns of seizure spread. Like patients, the earliest seizure activity in rats was recorded most frequently within the hippocampal formation. The ventral hippocampus and ventral subiculum displayed the earliest seizure activity. Amygdala, olfactory cortex, and septum occasionally displayed early seizure latencies, but not above chance levels. Substantia nigra and dorsomedial thalamus demonstrated consistently late seizure onsets, suggesting their unlikely involvement in seizure initiation. The results of the present study reveal similarities in onset sites of spontaneous seizures in patients with temporal lobe epilepsy and pilocarpine-treated rats that support the model's validity.

\section{Introduction}

In the United States, 1/26 people will develop epilepsy at some point in their lifetime (Institute of Medicine, 2012). The most common type of epilepsy in adults is temporal lobe epilepsy, which can be difficult to treat effectively (Engel et al., 1997). Laboratory animal models have been used in attempts to reveal underlying mechanisms and facilitate the discovery of more effective treatments. A variety of models exists, but the most commonly used are rodents in which status epilepticus is induced by systemic treatment with kainic acid or pilocarpine (Buckmaster, 2004). In these models, after recovering from status epilepticus, spontaneous seizures develop that continue for the rest of the animal's life. Epileptic rodents display patterns of neuronal loss and synaptic reorganization in the hippocampus similar to that of patients with temporal lobe epilepsy. However, consensus is lacking on the reliability and validity of laboratory animal models of

Received Jan. 31, 2013; revised May 3, 2013; accepted May 26, 2013.

Author contributions: I.T., M.R.B., and P.B. designed research; I.T., F.L., and P.S.B. performed research; M.R.B. contributed unpublished reagents/analytic tools; I.T., F.L., and P.S.B. analyzed data; I.T. and P.S.B. wrote the paper.

This work was supported by the National Institute of Neurological Disorders and Stroke-National Institutes of Health and the Office of the Director of the National Institutes of Health and the Epilepsy Foundation.

The authors declare no competing financial interests.

Correspondence should be addressed to Paul S. Buckmaster, 300 Pasteur Drive, R321 Edwards Building, Department of Comparative Medicine, Stanford University, Stanford, CA 94305. E-mail: psb@stanford.edu.

M.R. Bower's present address: Department of Neurology, Divisions of Clinical Neurophysiology and Epilepsy, Mayo Systems Electrophysiology Laboratory, Mayo Clinic, Rochester, MN 55905.

F. Leyva's present address: Long Island Veterinary Specialists, Plainview, NY 11803.

DOI:10.1523/JNEUROSCI.0472-13.2013

Copyright $\odot 2013$ the authors $\quad 0270-6474 / 13 / 3311100-16 \$ 15.00 / 0$ temporal lobe epilepsy (Lowenstein, 2011). Some have argued that spontaneous seizures in epileptic pilocarpine-treated rats initiate in brain regions different from those in patients (Mello et al., 1996; Harvey and Sloviter, 2005; Sloviter et al., 2007). In patients with temporal lobe epilepsy, spontaneous seizures are usually first recorded in the hippocampal formation, but sometimes in other structures, including the amygdala and temporal lobe neocortex (Quesney, 1986; Spencer et al., 1987, 1990; Sperling and O'Connor, 1989, '; Duckrow and Spencer, 1992; Spencer and Spencer, 1994; Spanedda et al., 1997; Wennberg et al., 2002). Previous studies with rodent models identified the ventral hippocampus, olfactory cortex, and amygdala (Bertram, 1997), the midline dorsal thalamus (Bertram et al., 2001), and specific parts of the hippocampal formation (Lévesque et al., 2012) as likely sites of seizure initiation. However, many other potential sites of seizure initiation have not yet been tested.

The present study used 32 recording electrodes per animal to investigate whether sites of seizure initiation in pilocarpinetreated epileptic rats are similar or different from those reported for patients. Brain regions were chosen for recording based in part on whether they display neuropathological changes. The hippocampal formation is damaged most consistently in temporal lobe epilepsy patients, with less frequent involvement of other structures such as the thalamus and amygdala (Sano and Malamud, 1953; Cavanagh and Meyer, 1956; Scholz, 1959; Falconer et al., 1964; Margerison and Corsellis, 1966; Du et al., 1993). In epileptic pilocarpine-treated rats, neuropathological changes are evident in brain regions similar to those reported for patients and 
in additional areas including olfactory cortex, substantia nigra, and septum (Turski et al., 1986). The present study investigated which of these structures generated the earliest electrographic seizure activity during spontaneous seizures in rats. The hypothesis was that sites of earliest seizure activity in the animal model would be similar to what has been reported for patients with temporal lobe epilepsy.

\section{Materials and Methods}

Animals. All experiments were performed in accordance with the National Institutes of Health Guide for the Care and Use of Laboratory Animals and were approved by a Stanford University institutional animal care and use committee. Male Sprague Dawley rats (Harlan Laboratories) 32-35 d of age were treated with pilocarpine $(380 \mathrm{mg} / \mathrm{kg}$, i.p.) $20 \mathrm{~min}$ after atropine methyl bromide ( $5 \mathrm{mg} / \mathrm{kg}$, i.p.). Diazepam (10 mg/kg, i.p.) was administered $2 \mathrm{~h}$ after onset of status epilepticus and repeated as needed. Diazepam treatment alone reduces mortality but does not immediately terminate status epilepticus (Martin and Kapur, 2008). Rats also received lactated Ringer's (10 ml, s.c.). Beginning 7-10 d after pilocarpine treatment, rats were videomonitored to confirm the development of spontaneous, recurrent seizures before implanting recording electrodes.

Brain regions targeted for recording were the septum (medial and lateral parts and the diagonal band of Broca), dorsomedial thalamus (mediodorsal thalamic nucleus and other nuclei of the midline thalamus: parventricular, parataenial, and nucleus reunions), amygdala (including the cortex-amygdala transition zone and amygdaloid-hippocampus), olfactory cortex (including the endopiriform nucleus, postpiriform transition area, and olfactory tubercle), dorsal and ventral hippocampus (induseum griseum, dentate gyrus, and CA1-3), substantia nigra (pars reticulata and compacta), and entorhinal cortex (medial and lateral parts). Nontargeted structures were sometimes recorded, because a targeted region was missed or because a bipolar recording electrode had one tip in the targeted region and the other tip in a different region above or below. Nontargeted regions included the cerebral peduncle, neocortex (cingulate and insular cortex), corpus striatum (caudate/putamen and nucleus accumbens), ventral subiculum (pre-, post-, and parasubiculum), and other parts of dorsal thalamus not contained within the dorsomedial group described above and other diencephalic regions (zona incerta, reticular nucleus, subthalamic nucleus, and hypothalamus).

To implant electrodes, rats were sedated with diazepam (10 mg/kg, i.p.), anesthetized with isoflurane (1.5\%), placed in a stereotaxic frame, maintained on a heating pad with feedback control, given antibiotic (enrofloxacin, $10 \mathrm{mg} / \mathrm{kg}$, s.c.), and prepared for aseptic surgery. Bipolar electrodes consisted of $25 \mu \mathrm{m}$ diameter $\mathrm{H}$-formvar-coated stainless steel wires (California Wire Company) glued together so tips were $1 \mathrm{~mm}$ apart. In each rat, 16 bipolar electrodes were directed toward the following brain regions bilaterally (anterior-posterior and medial-lateral stereotactic coordinates in $\mathrm{mm}$ are referenced to bregma and to the brain surface for depth): septum $(0.7$, $0.3,5.9)$, dorsomedial thalamus $(-3.0,0.8,6.0)$, amygdala $(-2.8,4.4,7.9)$, olfactory cortex $(-2.8,5.8,7.4)$, dorsal hippocampus $(-4.6,2.6,3.1)$, substantia nigra pars reticulata $(-5.3,2.4,7.6)$, ventral hippocampus $(-5.5,4.8$, $7.1)$, and medial entorhinal cortex $(-7.9,5.0,5.3)$. A reference electrode was placed in the cerebellum. The ground consisted of screws in the skull rostral to bregma and caudal to lambda. Electrodes were connected to an interface board in a protective covering (NLX 9 drive; Neuralynx), which was affixed to the skull with cranioplastic cement and jeweler's screws. After surgery, rats received lactated Ringer's solution (10 ml, s.c.) and analgesic (buprenorphine, $0.05 \mathrm{mg} / \mathrm{kg}$, s.c.).

Recording. Local field potential and time-locked video recording of spontaneous seizures began $7 \mathrm{~d}$ after surgery, which was an average of $188 \mathrm{~d}$ (range, 71-286 d) after pilocarpine treatment. Recordings were obtained during the day. Signals were buffered with a head stage (HS-36; Neuralynx), amplified, digitized, filtered $(0.1-1800 \mathrm{~Hz})$, sampled $(2000 \mathrm{~Hz}$; Cheetah Data Acquisition; Neuralynx), and saved for offline analysis. Recordings were obtained $\sim 8.5 \mathrm{~h} / \mathrm{d}$ and $6 \mathrm{~d} /$ week and continued for an average of $9 \mathrm{~d}$ (range, 5-28 d). Average total time recorded per rat was $76 \mathrm{~h}$ (range, 43-252 h).

Histology. After recording a sufficient number of spontaneous seizures, rats were killed with urethane $(2 \mathrm{~g} / \mathrm{kg}$, i.p.) and perfused at 30 $\mathrm{ml} / \mathrm{min}$ through the ascending aorta for 2 min with $0.9 \% \mathrm{NaCl}$ and 30 min with $4 \%$ formaldehyde in $0.1 \mathrm{~m} \mathrm{~PB}, \mathrm{pH} 7.4$. Brains were removed and stored in fixative at $4^{\circ} \mathrm{C}$ at least overnight and were equilibrated in $30 \%$ sucrose in $0.1 \mathrm{M} \mathrm{PB}$. Brains were sectioned coronally using a sliding microtome set at $40-55 \mu \mathrm{m}$. Continuous series of sections were stained with $0.25 \%$ thionin. Electrode tracks were evaluated to identify recording sites. If a track of a given electrode could not be reliably traced to specify the location of its tip, data acquired from that electrode were omitted from analysis.

Seizure onset identification. To identify seizure onsets, a rat's daily recording file first was evaluated by examining local field potential recordings from 5 to 6 randomly chosen brain regions to identify seizures. As in previous studies (Bragin et al., 2005), only seizures that lasted $>10$ s were analyzed. Therefore, findings of the present study might not pertain to shorter seizures. For each seizure identified, corresponding video was reviewed to measure behavioral severity based on Racine's scale (Racine, 1972). Stages 0-2 were classified as nonconvulsive; stages $3-5$ were classified as convulsive. Next, from each of the 10 animals, 10 seizures were chosen randomly for detailed evaluation of behavioral and electrographic seizure onset times. When possible, five convulsive and five nonconvulsive seizures were sampled for each rat. An algorithm in MATLAB (MathWorks) was used to isolate epochs spanning from $10 \mathrm{~min}$ before to 3 min after the approximate seizure onset time for each electrode's signal. The algorithm also randomly assigned a number to each electrode's signal so that the examiner was blind to brain regions during analysis.

For each electrode, electrographic seizure onset time was identified as described previously (Bower and Buckmaster, 2008). One electrode at a time, a seizure onset window was bracketed by manually identifying the latest time of normal activity and the earliest time of clear seizure activity (Fig. 2A). Within the bracketed period, seizure onset was estimated using four methods. The first was a subjective by-eye approach to determine the earliest appearance of a persistent change that developed into clear seizure activity. Next, three objective measures of seizure onset were computed. One used low-pass filtering (cutoff, $1 \mathrm{~Hz}$ ) to identify a slow wave (Bragin et al., 2005), which was the peak of the largest voltage change within the seizure onset window. The other two seizure onset markers were based on spectrograms, which were computed using discrete prolate spheroids (pmtm function in MATLAB). Two frequency windows were examined. The peak of the summed spectral power for low frequencies $(20-200 \mathrm{~Hz})$ looked for changes primarily in the gamma frequency band. The peak of the summed spectral power for high frequencies $(200-600 \mathrm{~Hz})$ looked for changes in frequency ranges previously associated with seizure onset (Bragin et al., 2005). Analysis did not include specific identification of high-frequency oscillations. For both frequency bands, summed spectral power was smoothed with a low-pass filter (cutoff, $1 \mathrm{~Hz}$ ). Although all four onset measures were detected for each seizure, only the earliest was used as the final estimate of electrographic seizure onset for that electrode.

Statistical analysis. SigmaStat software (Systat Software) was used for statistical analyses, and $p<0.05$ was considered significant. Error bars in the figures represent SEM.

\section{Results}

\section{Brain regions recorded}

Rats had $27.8 \pm 1.2$ (mean \pm SEM; range, 23-31) useful recording electrodes with tracks in Nissl stained sections that could be followed to identify recorded brain regions (Fig. 1). In each of the 10 epileptic rats, five to eight of the eight targeted brain regions (septum, dorsomedial thalamus, amygdala, olfactory cortex, dorsal hippocampus, substantia nigra, ventral hippocampus, and entorhinal cortex) contained at least one recording electrode tip (Table 1). Of the 278 total useful electrodes in 10 rats, $68 \%$ were in targeted regions. The remaining electrodes were in nontargeted brain regions (subiculum, nondorsomedial thalamus, cerebral peduncle, neocortex, and corpus striatum), which were included in seizure onset analysis. 

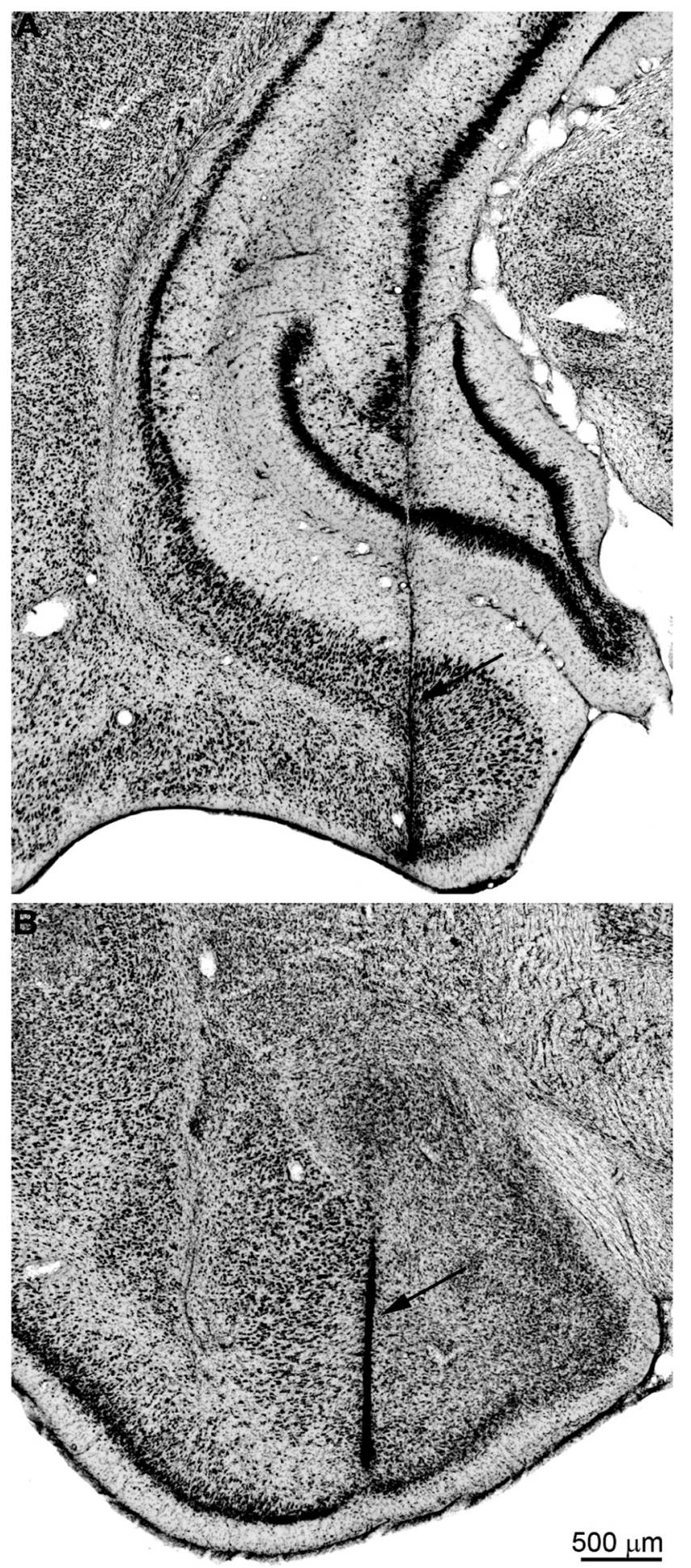

Figure 1. Recording electrode tracks in regions that displayed earliest seizure activity. $\boldsymbol{A}$, Site of the short electrode (arrow), located $1 \mathrm{~mm}$ up from the tip of the long electrode of the pair, was in the right subiculum of rat no. 3 , in which seizure activity was recorded earliest during 4/10 seizures. $\boldsymbol{B}$, The site of the short electrode (arrow) was in the right amygdala of rat no. 5 , in which seizure activity was recorded earliest in $2 / 10$ seizures, and 2 more seizures were recorded first in the same amygdala at other recording sites.

\section{Seizure characteristics}

Spontaneous seizures were recorded simultaneously by electrodes in multiple brain regions (Fig. 2A). For each seizure, each electrode was analyzed individually. Seizure onset windows, bracketed by the latest normal electrographic activity and the earliest clear seizure activity, lasted $11.3 \pm 0.1 \mathrm{~s}$ (mean $\pm \mathrm{SEM}$; median, $10.2 \mathrm{~s}$; range, 2.1-64.5 s). Within windows, seizure onsets were defined as the earliest of four markers. The earliest marker was determined by eye in $72.8 \%$ of the cases. Although the exact electrographic appearance of the seizure onset varied depending on structure and location within a structure, seizures typically began with a period of low-amplitude, high-frequency oscillations, which developed into high-amplitude, low-frequency oscillations (Figs. 2A, B, 3). Occasionally, short bursts of high-amplitude spikes were observed in the initial period. These seizure onset patterns are similar to what has been reported for patients with temporal lobe epilepsy (Engel, 1990; Spencer et al., 1990, 1992; Brekelmans et al., 1995; Velasco et al., 2000; Weinand et al., 2007; Götz-Trabert et al., 2008; Ogren et al., 2009) and in rodent models (Bragin et al., 1999, 2005), including pilocarpine-treated rats (Lévesque et al., 2012).

The slow wave was the earliest marker in $18.3 \%$ of seizures. Peaks in spectral power in the 20-200 and 200-600 Hz frequency bands were earliest in $4.9 \%$ and $4.1 \%$ of seizures, respectively. The maximum time between the earliest and latest seizure onset marker was $4.2 \pm 0.1 \mathrm{~s}$ (median, $3.0 \mathrm{~s}$; range, 0.1-35.7 s). These findings reveal that by-eye identification of seizure onset was usually earliest, with other seizure onset markers following within $<3-4$ s in most cases.

Seizure offsets were identified by abrupt termination in activity (Figs. 2A, 3), which also occurs in patients (Kramer et al., 2012). Seizure duration was calculated by the difference in seizure onset and offset for each channel. Durations of all recording channels were then averaged to yield a single duration for each seizure. Across all 10 rats, seizure duration was $63.9 \pm 4.0 \mathrm{~s}$ (range, 20.0-233.5 s; Fig. 2C). Across all individual recording electrodes in all 10 rats, seizure duration ranged from 0 in those cases when seizure activity did not spread to an electrode $(n=8)$ to $230.3 \mathrm{~s}$. Therefore, seizure duration was variable, but always $<4$ min and on average $\sim 1$ min long. These findings are similar to those reported previously for epileptic pilocarpine-treated rats (Lévesque et al., 2012) and they suggest that seizures in the animal model are only approximately half as long as those of patients with temporal lobe epilepsy (Brekelmans et al., 1995; Spencer et al., 1999; Afra et al., 2008; Zangaladze et al., 2008).

During the entire recording period a total of 616 seizures $(62.9$ seizures/rat; range, 15-98) were recorded that could be evaluated for behavior. These seizures include the 10 per rat that were used for detailed analysis plus other recorded seizures. Seizures were convulsive (Racine scale $\geq 3$ ) $47-100 \%$ of the time depending on the rat (mean, 76\%). Similarly, kainate-treated epileptic rats have a substantial proportion of convulsive seizures (Williams et al., 2009). A subset of 100 seizures ( 10 in each of 10 rats) was analyzed in detail. In 2/10 rats, only convulsive seizures were observed. In patients, electrographic seizures in mesial temporal regions frequently do not cause generalized convulsions or even milder behavioral alterations (Quesney, 1986; French et al., 1993; Wennberg et al., 2002; Zangaladze et al., 2008). Epileptic pilocarpinetreated rats therefore appear to have a higher proportion of generalized convulsions than do patients with temporal lobe epilepsy. In rats, seizure duration was similar for convulsive (64.7 $\pm 4.9 \mathrm{~s}$; range, $21.8-233.5 \mathrm{~s} ; n=10$ rats, 66 seizures) and nonconvulsive seizures $(62.2 \pm 6.9 \mathrm{~s}$; range, $20.0-175.2 \mathrm{~s} ; n=8$ rats, 34 seizures).

Behavioral seizure onsets were identified by the earliest repetitive movements, which frequently involved twitching of whiskers, eyelids, and ears. Behavioral seizure onset was measured with respect to electrographic seizure onset. In 63/66 convulsive 
Table 1. Number of recording electrodes in targeted and nontargeted brain regions of the left and right brain in individually identified rats

\begin{tabular}{|c|c|c|c|c|c|c|c|c|c|c|}
\hline & \multicolumn{10}{|c|}{ Rat no. } \\
\hline & 1 & 2 & 3 & 4 & 5 & 6 & 7 & 8 & 9 & 10 \\
\hline \multicolumn{11}{|l|}{ Left } \\
\hline Amygdala & 3 & 1 & 1 & 2 & 3 & & 1 & & 3 & 3 \\
\hline Septum & 4 & 2 & & & & 1 & 2 & & 2 & 2 \\
\hline Dorsal hippocampus & 1 & 2 & 2 & 2 & 2 & 1 & & 1 & & 2 \\
\hline Olfactory cortex & 1 & 2 & 2 & 1 & & & 4 & 2 & 1 & 2 \\
\hline Entorhinal cortex & 2 & 1 & 1 & & 2 & & 2 & 1 & & 1 \\
\hline Ventral hippocampus & 1 & & 1 & 3 & & 1 & & & 1 & 1 \\
\hline Dorsomedial thalamus & 1 & & 1 & 1 & 1 & & 1 & & 1 & \\
\hline Substantia nigra & 1 & 1 & & & 2 & 1 & 1 & & 1 & \\
\hline Subiculum & 1 & 2 & 2 & 1 & 2 & 3 & 1 & 1 & 2 & 1 \\
\hline Nondorsomedial thalamus & 2 & 2 & 2 & 2 & 2 & 1 & 3 & 3 & 2 & 3 \\
\hline Cerebral peduncle & & 1 & 1 & & & 1 & & & & 1 \\
\hline Neocortex & & & & & & & & & 1 & \\
\hline Corpus striatum & & & 1 & & 1 & & & & & \\
\hline \multicolumn{11}{|l|}{ Right } \\
\hline Amygdala & 3 & 2 & 2 & & 3 & & & 1 & 3 & 3 \\
\hline Septum & & 2 & 2 & 2 & 2 & 1 & 2 & 2 & & 2 \\
\hline Dorsal hippocampus & 1 & 1 & 1 & 2 & 2 & 2 & & 2 & 2 & 2 \\
\hline Olfactory cortex & 2 & 4 & 2 & 3 & 3 & & 5 & 1 & 1 & 2 \\
\hline Entorhinal cortex & 1 & 1 & 2 & & 1 & & 1 & 1 & 1 & 2 \\
\hline Ventral hippocampus & 1 & & & 4 & & 1 & & & 1 & 1 \\
\hline Dorsomedial thalamus & & & 1 & & 1 & 1 & & & 1 & \\
\hline Substantia nigra & 1 & 1 & 1 & 1 & 1 & 1 & 1 & 1 & & \\
\hline Subiculum & 1 & 1 & 2 & & 1 & 2 & 2 & 3 & 1 & \\
\hline Nondorsomedial thalamus & 3 & 3 & 2 & 3 & 1 & 1 & 4 & 2 & 3 & 2 \\
\hline Cerebral peduncle & & & & & & 1 & & 1 & & 1 \\
\hline Neocortex & & & 2 & & & & & 1 & 1 & \\
\hline
\end{tabular}

seizures (Racine scale $\geq 3$ ), video recordings were available for analysis and behavioral seizure onsets were identified. In all 34 nonconvulsive seizures, video recordings were available and mild behavioral components (Racine scale 1-2) could be used to measure onset latency in 31 . Across all 10 rats, the latency from electrographic to behavioral seizure onset was $5.0 \pm 1.0 \mathrm{~s}$ (range, 0.3-10.5 s; Fig. 2D). Electrographic seizure onset was the earliest onset of all electrodes in the animal. In patients with temporal lobe epilepsy, the average time from electrographic seizure onset to clinical seizure onset is approximately three times longer (Quesney, 1986; Weinand et al., 2007; Götz-Trabert et al., 2008). Across all 94 seizures that had a behavioral component that could be analyzed, latency to behavioral onset ranged from -13.1 to $31.4 \mathrm{~s}$. Negative values indicate that seizure behavior preceded the electrographic onset, which also has been observed in patients with depth electrodes (Weinand et al., 2007). In epileptic pilocarpine-treated rats, 3/94 seizures had behavioral onsets that preceded the electrographic onset $(-0.8 \mathrm{~s},-2.2 \mathrm{~s}$, and $-13.1 \mathrm{~s})$. Initial movements at the onset of behavioral seizures were easy to miss when rats were not facing the camera. Therefore, to get a potentially more accurate measurement, average behavioral seizure onset latency was recalculated using only those cases in which rats were facing the camera at the beginning of the seizure. None of the resulting behavioral seizure onset latencies preceded electrographic onsets and the mean latency was longer $(6.8 \pm$ $1.2 \mathrm{~s}$; range, 3.4-9.4 s; $n=5$ rats, 30 seizures) compared with the complete dataset, but the difference was not statistically significant. Using only those seizures in which rats faced the camera, the behavioral onset latency of nonconvulsive seizures $(11.4 \pm 1.4 \mathrm{~s}$; range, 8.7-14.0 s; $n=4$ rats, 11 seizures) was longer than that of convulsive seizures $(3.8 \pm 1.0 \mathrm{~s}$; range, $1.1-5.7 \mathrm{~s}, n=4$ rats, 19 seizures; $p=0.005, t$ test). In summary, these findings indicate that in at least $97 \%$ of cases, the beginning of electrographic sei- zure activity was recorded before behavioral manifestations in epileptic pilocarpine-treated rats.

\section{Electrographic seizure spread}

In 95/100 seizures in 10 rats, seizure activity spread to all recorded brain regions (Fig. $2 A$ ), whereas in 5/100 seizures in 3 rats, electrographic seizure activity failed to spread to every recorded structure. For example, the septum was not involved in a seizure in rat no. 3 (Fig. 3). However, on the same day in the same rat, another seizure included the septum. Structures that failed to show electrographic seizure activity included the septum $(1 \times)$, substantia nigra pars compacta $(1 \times)$, dorsal hippocampus $(1 \times)$, cerebral peduncle $(1 \times)$, dorsomedial thalamus $(2 \times)$, and nondorsomedial thalamic regions $(2 \times)$. These findings reveal that in rats seizure activity usually spreads to all recorded structures. In contrast, the spread of seizure activity tends to be confined to a more limited subset of brain regions in patients with temporal lobe epilepsy (Lieb et al., 1976; Spencer et al., 1987, 1990; Sperling and O'Connor, 1990; Wennberg et al., 2002).

To measure the pattern and timing of seizure initiation and spread, electrographic seizure onsets were identified for each recording electrode. The temporal resolution of the recording method (0.1-1800 Hz filtering, $2000 \mathrm{~Hz}$ sampling) was adequate to identify differences in timing of seizure onsets in different brain regions (Fig. $2 B$ ). Earliest seizure activity was recorded at least once in $6 / 8$ targeted and in in $1 / 5$ nontargeted brain regions (subiculum; Fig. 4A). Earliest seizure activity was recorded most often in the subiculum; frequently in other parts of the hippocampal formation (ventral hippocampus, dorsal hippocampus, and entorhinal cortex); occasionally in the amygdala and olfactory cortex; rarely in the septum; and never in the dorsomedial thalamus, substantia nigra, cerebral peduncle, corpus striatum, neocortex, or nondorsomedial thalamus. However, there 


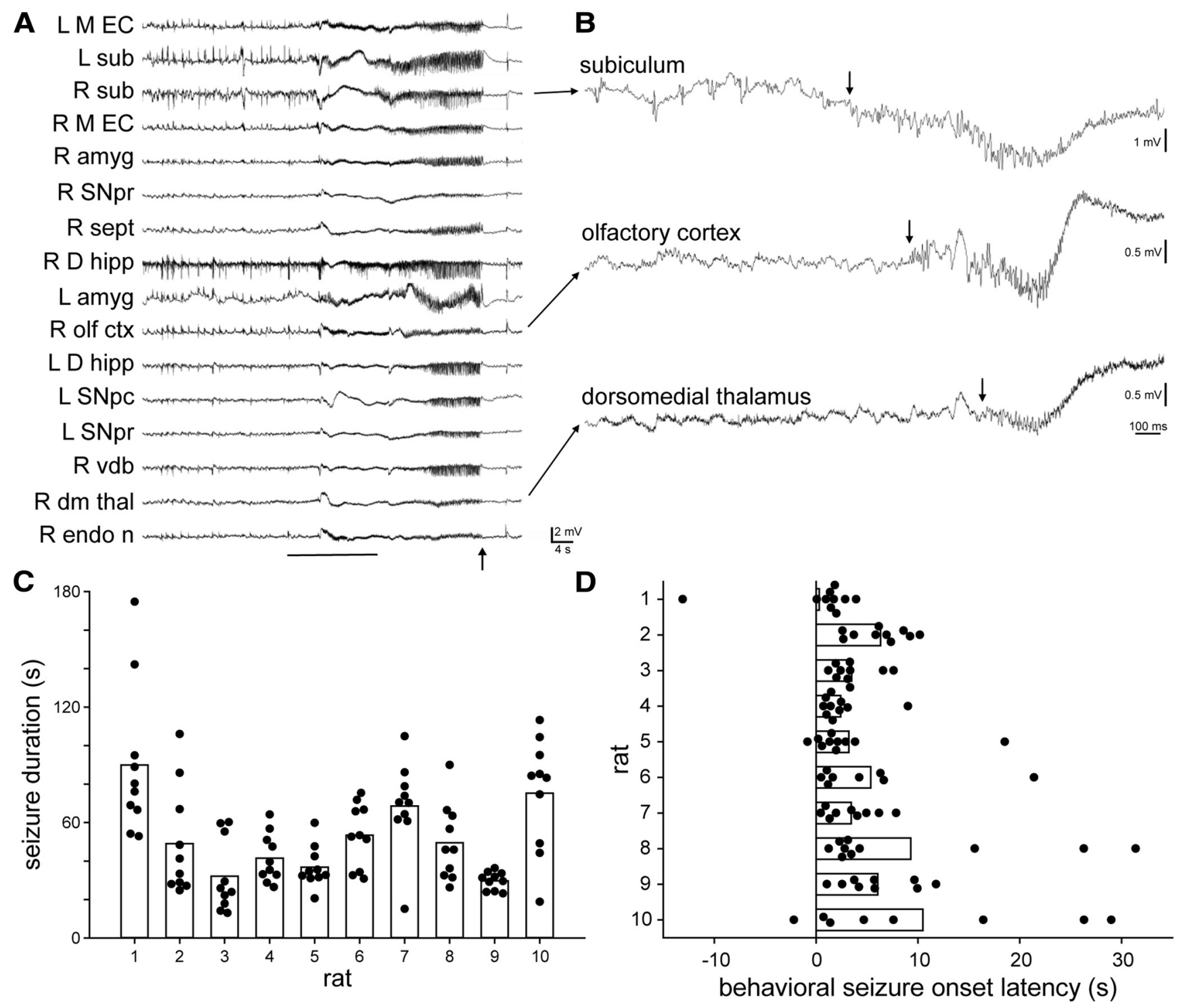

Figure 2. Spontaneous seizures in epileptic pilocarpine-treated rats. A, Seizures spread quickly and extensively. Recordings from a subset of $16 / 32$ electrodes implanted in various brain regions. The approximate seizure offset (arrow) and onset window (bar), bracketed by the latest normal activity and earliest clear seizure activity, are indicated. L indicates left; $M$, medial; EC, entorhinal cortex; sub, subiculum; R, right; amyg, amygdala; $S \mathrm{Npr} /$ c, substantia nigra pars reticulata/compacta; sept, septum; D, dorsal; hipp, hippocampus; olf ctx, olfactory cortex; vdb, ventral diagonal band; $\mathrm{dm}$ thal, dorsomedial thalamus; endo n, endopiriform nucleus. B, Precise seizure onsets (arrows) in three regions. C, Seizure durations. Bars represent averages; symbols indicate durations of individual seizures. $\boldsymbol{D}$, Behavioral seizure onset latencies. Electrographic seizure onset is at 0 . Positive (negative) values indicate that behavioral onset followed (preceded) electrographic onset. Bars represent averages; symbols indicate individual seizures.

was variability in electrode sampling of brain regions (Table 1). Some of the 10 rats did not have electrodes in all regions, resulting in $<100$ seizures available for analysis in those regions (Fig. $4 B$ ). In addition, the total number of electrodes varied by brain region (Fig. 4C). Therefore, to account for differences in electrode sampling of brain regions, the expected probability of recording earliest seizure activity (assuming seizure onset sites were random) was calculated (Fig. 4D). For example, 60 seizures were recorded with at least one electrode in the ventral hippocampus. A total of 16 recording electrodes were implanted in the ventral hippocampus of all rats combined. Therefore, the ventral hippocampus had $60 \times 16=960$ possibilities for recording seizure onsets. Repeating this process for all brain regions yielded a total of 24,450 recording possibilities. If sites of seizure onset were random, one would expect the ventral hippocampus to record earliest seizure activity with a probability of $960 / 24,450=0.039$. Dividing ob- served earliest seizure onset probabilities by expected revealed that the ventral hippocampus recorded earliest seizure activity more than four times more often than predicted by chance (Fig. $4 E$ ). The subiculum and dorsal hippocampus also displayed more of the earliest seizure recordings than expected; the septum and nondorsomedial thalamus displayed fewer than expected; other regions were not significantly different from chance ( $t$ test). These findings indicate that earliest seizure activity was most likely to be recorded in the hippocampus and subiculum.

To determine whether seizures initiated consistently at specific sites and to examine patterns of seizure spread, the order of seizure onset was plotted by individual recording sites (Figs. 5, 6). In $7 / 10$ rats, seizures were equally likely to be recorded first in either hemisphere. However, in 3/10 rats (rat nos. 3, 4, and 10) seizures were more likely to be recorded earliest in one hemisphere ( $p<0.05, t$ test). There was no single recording site that 

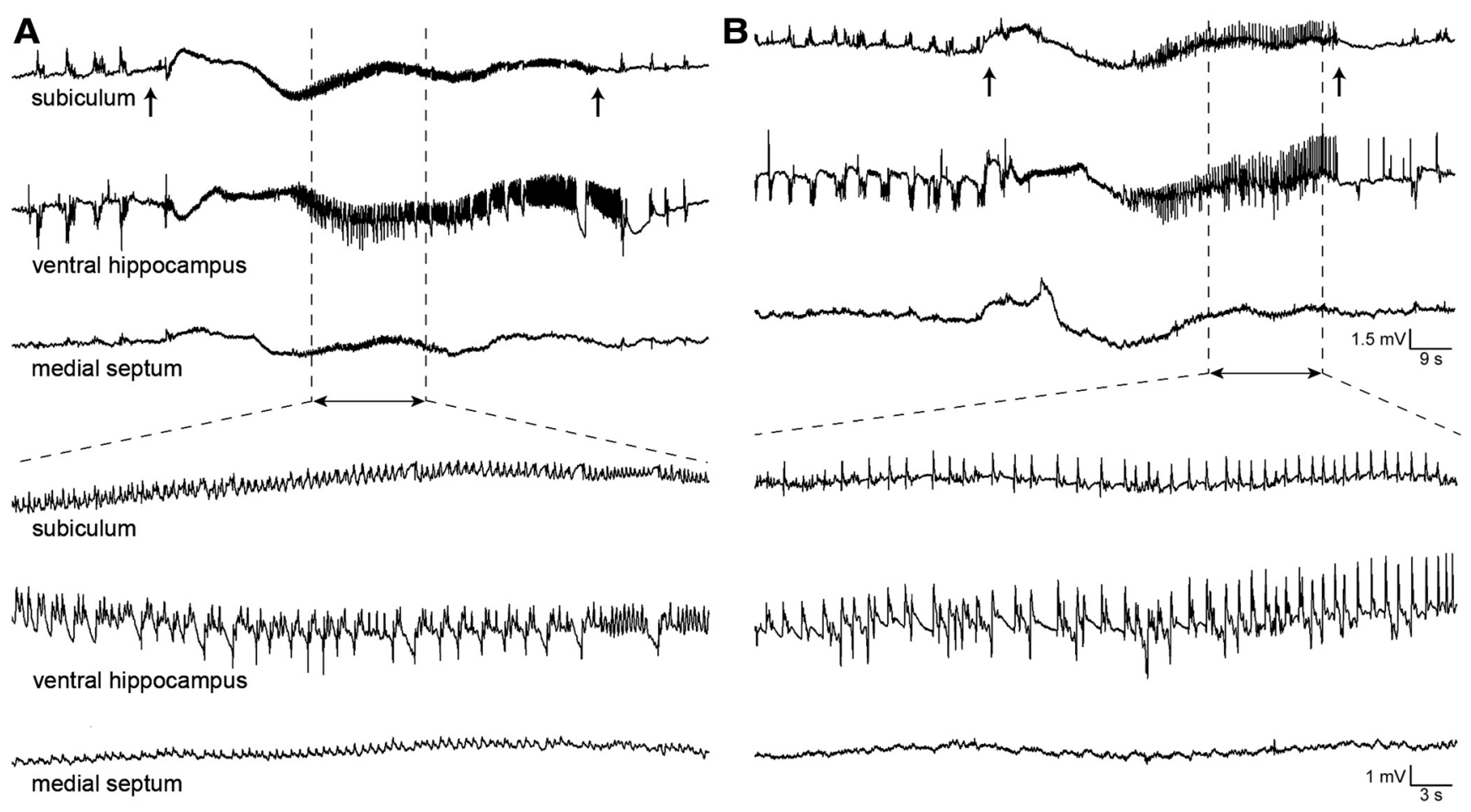

Figure 3. Seizures occasionally failed to spread to all recorded structures. $A$, Seizure that spread to all recorded regions, including the medial septum, which displays $5-8 \mathrm{~Hz}$ seizure activity. Seizure onset and offset for the subiculum are indicated by arrows. $\boldsymbol{B}$, Seizure recorded from the same rat on the same day that did not spread to medial septum.

always initiated a seizure within a rat. However, some recording sites showed earliest seizure onsets repeatedly. For example, in rat no. 4 , the earliest seizure onset was recorded in $4 / 10$ seizures by an electrode in the right ventral hippocampus and in 2/10 seizures by a different electrode in the same right, ventral hippocampal region (Fig. 5). Like these 2 electrodes in rat no. 4 that recorded the earliest seizure activity during multiple seizures, for the entire group of rats, 58/100 seizures were recorded by electrodes that detected earliest seizure activity multiple times; conversely, individual electrodes recorded the earliest seizure activity only once in 42/100 seizures. These findings indicate variability in sites of earliest recorded seizure activity in individual rats. Similarly, in individual patients with temporal lobe epilepsy, sites of earliest recorded seizure activity vary (Lieb et al., 1976; Spencer et al., 1990; Spencer and Spencer, 1994; Spencer, 1998, 2002). However, some evidence suggests that, compared with rats, a larger percentage of each patient's seizures has a uniform seizure onset location (Spencer et al., 1987, 1999; Götz-Trabert et al., 2008).

Once initiated, seizures tended to spread first within the same brain region and among closely connected ipsilateral and contralateral structures. For example, in many rats, most seizures were recorded earliest in part of the hippocampal formation and other parts of the hippocampal formation tended to display seizure activity next, evident as warm colored lines in Figure 5 and Figure 6. In contrast, more delayed spread of seizure activity is indicated by cold colored lines among dorsomedial and nondorsomedial thalamus, substantia nigra, septum, corpus striatum, and neocortical regions. However, there was no completely consistent pattern of spread of electrographic seizure activity among structures within or across rats. If seizure spread had been fixed and consistent within an individual, plots that included all 10 seizures/rat (Figs. 5A2, 6) would have shown a set of lines that exactly overlapped 10 times, once for each seizure. Instead, all plots consisted of many lines, indicating variable patterns of spread from seizure to seizure. For example, in rat no. 4, seizure activity was recorded earliest in the same site within the right ventral hippocampus during 4 different seizures, but regions that showed the second earliest seizure onset varied in all 4 seizures: left ventral hippocampus, left subiculum, right ventral hippocampus, and right dorsal hippocampus (Fig. 5, left). Similarly, individual patients with temporal lobe epilepsy have seizures with variable patterns of spread (Lieb et al., 1976; Spencer et al., 1987; but see Brekelmans et al., 1995; Wennberg et al., 2002; Götz-Trabert et al., 2008).

To quantify initiation and spread of seizure activity, latencies of earliest seizure onset were plotted for every recorded region (Fig. 7). Data plotted are the earliest recorded seizure activity for each region. In other words, if a region (including both sides of the brain) were recorded by multiple electrodes, only the earliest seizure activity of all electrodes in that region was used for this analysis. If a single region showed the earliest recorded seizure activity every time, mean onset latency for the region would be 0 . At the other extreme, if all regions randomly displayed earliest recorded seizure activity, average onset latency would be $>0$ and similar for all regions. Neither extreme was the case. Instead, regions showed a range of onset latencies. The regions with the earliest average seizure latencies were the subiculum (3/10 rats), ventral hippocampus (3/10 rats), dorsal hippocampus (1/10 rats), entorhinal cortex (1/10 rats), amygdala ( $1 / 10$ rats), and olfactory cortex (1/10 rats). Therefore, regions within the hippocampal formation displayed earliest average seizure onset latencies in $8 / 10$ rats. In the two rats in which earliest average seizure onset latency was in the amygdala or olfactory cortex, regions of the hippocampal formation had the next earliest latencies. When data from all 10 rats were ranked and averaged, the subiculum had the earliest seizure onsets, followed by other regions of the hippocampal forma- 

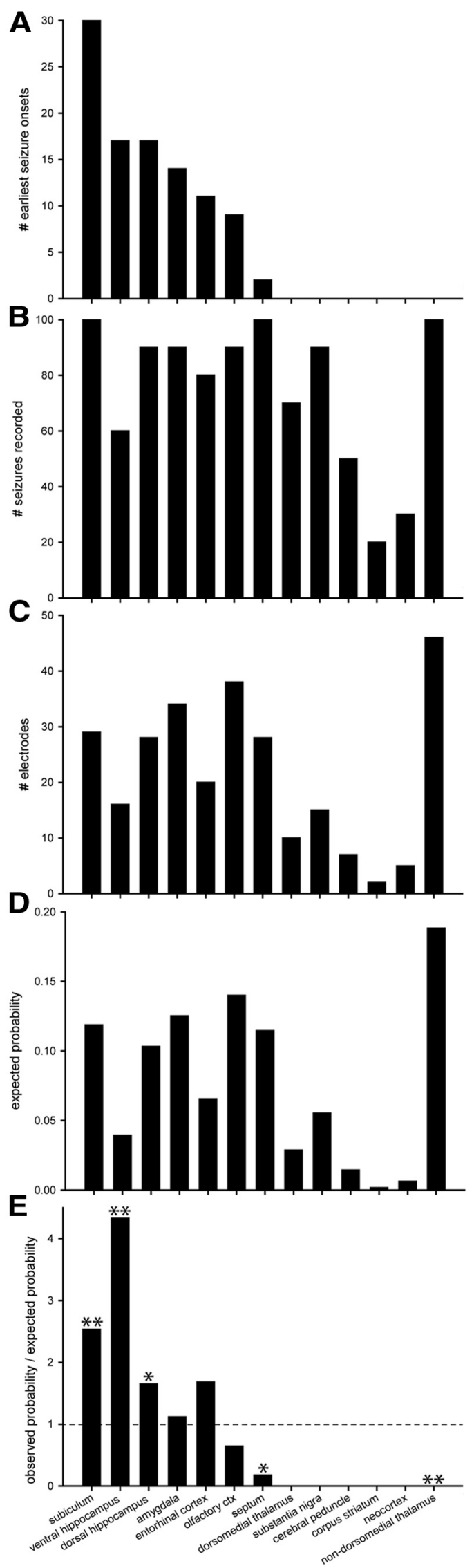

Figure 4. Seizure onsets were recorded significantly earlier in some brain regions than in others. $\boldsymbol{A}$, Number of seizure onsets recorded earliest in each recorded brain region. $\boldsymbol{B}$, Number of recordings in each brain region. Regions that did not contain recording electrodes in all 10 rats tion (ventral hippocampus, entorhinal cortex, and dorsal hippocampus), and then amygdala and olfactory cortex before the remaining regions (Fig. $8 A$ ).

Results of seizure onset latency measurements were evaluated statistically (Table 2). Regions within the hippocampal formation most frequently had significantly shorter seizure onset latencies than at least one other region. In some rats, the amygdala, olfactory cortex, nondorsomedial thalamus, and septum had seizure onset latencies that were significantly shorter than at least one other region, but in other rats, the same regions had significantly longer latencies. The substantia nigra, corpus striatum, cerebral peduncle, and dorsomedial thalamus were almost always significantly late.

To determine whether seizure onset latency values were dependent on by-eye identification, results were reanalyzed after omitting the by-eye onset data so that earliest seizure onset was determined only by objective measures (slow wave or peaks of summed spectral power in the $20-200$ or $200-600 \mathrm{~Hz}$ bands). Results were similar to those that included by-eye onset measurements. The ventral hippocampus had the earliest seizure onset ranking, followed by other parts of the hippocampal formation and then amygdala and olfactory cortex before other regions (Fig. 8B).

The analysis described above used the earliest recorded seizure activity of all electrodes within each region. However, the number of recording electrodes varied from region to region (Table 1), resulting in sampling bias. If sites of seizure onset were random, the region with the most electrodes would have the highest probability of showing the earliest seizure activity. To control for this confounding variable, the average (instead of the earliest) seizure onset latency was calculated for each region (Fig. 8C). Again, regions of the hippocampal formation ranked first, then amygdala and olfactory cortex, followed by the rest. Mean seizure onset latencies were consistently longer in the substantia nigra, dorsomedial thalamus, and nontargeted regions except subiculum. These findings reveal that early seizure activity is most frequently recorded in the hippocampal formation, more rarely in the amygdala or olfactory cortex, and not in the substantia nigra and dorsomedial thalamus.

The time required for a seizure to spread from the first to the last recorded structure varied from seizure to seizure within and across rats. For example, in rat no. 8 , differences in onset latencies from the first to the last structure were $<5 \mathrm{~s}$ in 8 seizures, but $2-5$ times longer in 2 other seizures (Fig. $7 H$ ). Other rats showed similar patterns. When the spread of a seizure was substantially delayed, the latency from one region to the next tended to be nonlinear. Usually, seizure activity took longer to spread from the first region, then spread quickly among later structures (Fig. $7 D-F, H, I$ ). In other cases, seizures appeared to spread quickly among 2-4 structures initially, then stalled before spreading rapidly among remaining structures (Fig. $7 E-H, J$ ). Overall, the average onset latency from the earliest to the latest recorded structure was $6.5 \pm 0.7 \mathrm{~s}$ (median, $4.3 \mathrm{~s}$; range, $0.4-33.0 \mathrm{~s}$ ). Seizures in patients with temporal lobe epilepsy are reported to take more than twice as long to spread even less extensively (Quesney, 1986; Spencer et al., 1987, 1999; Brekelmans et al., 1995; Götz-Trabert et al., 2008). The time for seizure

had $<100$ seizures recorded. C, Total number of recording electrodes for all 10 rats in each brain region. $\boldsymbol{D}$, Expected probability of recording earliest seizure activity based on extent of sampling of each brain region if onset sites were random. $\boldsymbol{E}$, Ratio of observed probability to expected probability of earliest seizure activity. Values above (below) dashed line indicate more (fewer) earliest seizure onsets than expected by chance. ${ }^{*} p<0.05,{ }^{* *} p<0.01, t$ test. 

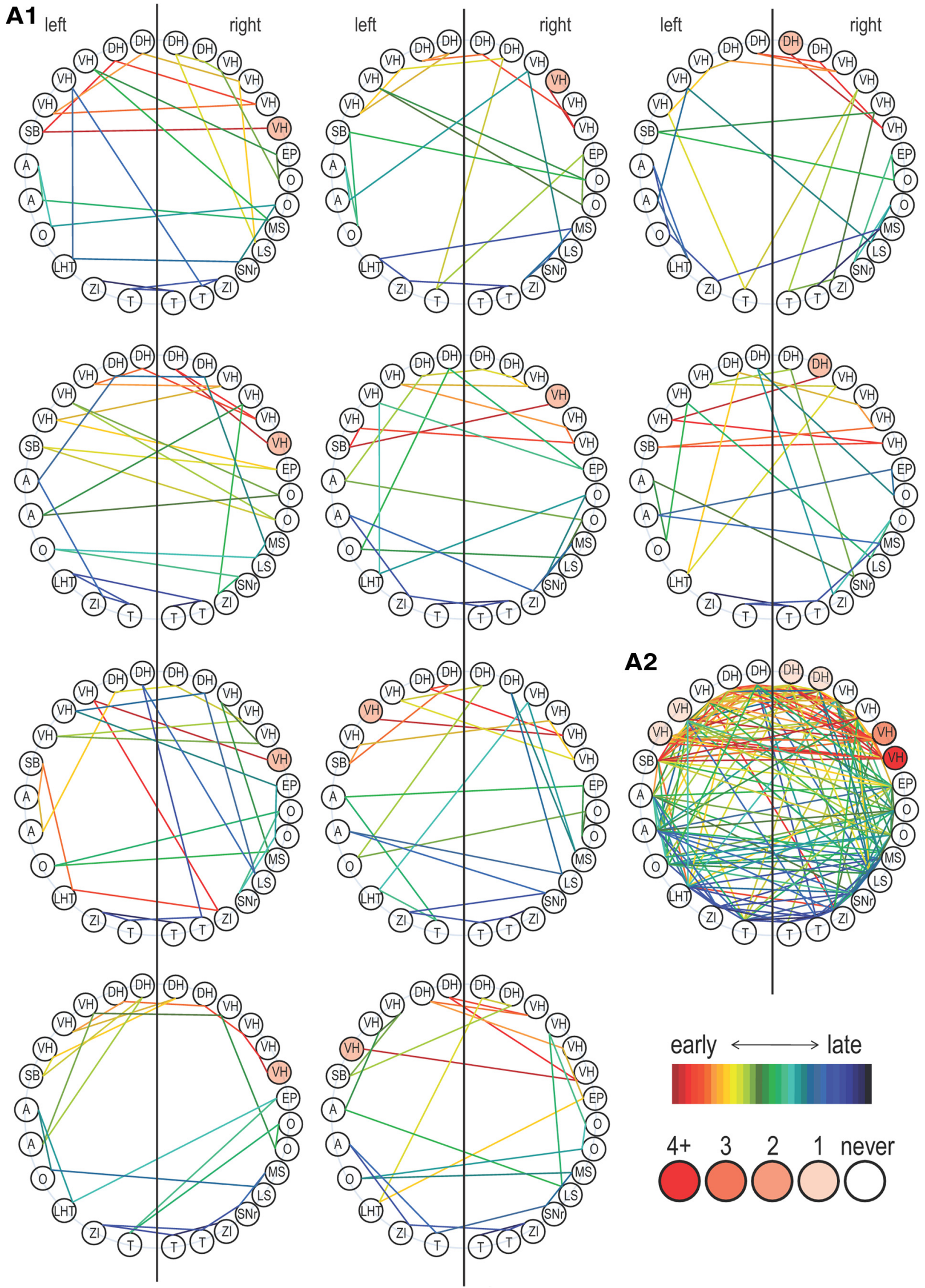

Figure 5. Sites of seizure initiation and patterns of spread among recorded structures. $\boldsymbol{A} 1$, Results of 10 seizures from rat no. 4. Sites that showed earliest recorded seizure activity are indicated (pink circles). In four seizures (left column) the same electrode within the right ventral hippocampus (VH) recorded the earliest evidence of seizure activity. Another electrode within the right ventral hippocampus recorded the earliest evidence of seizure activity twice (middle column). Line color indicates sequence of spread. A2, All 10 seizures of rat no. 4. Number (Figure legend continues.) 

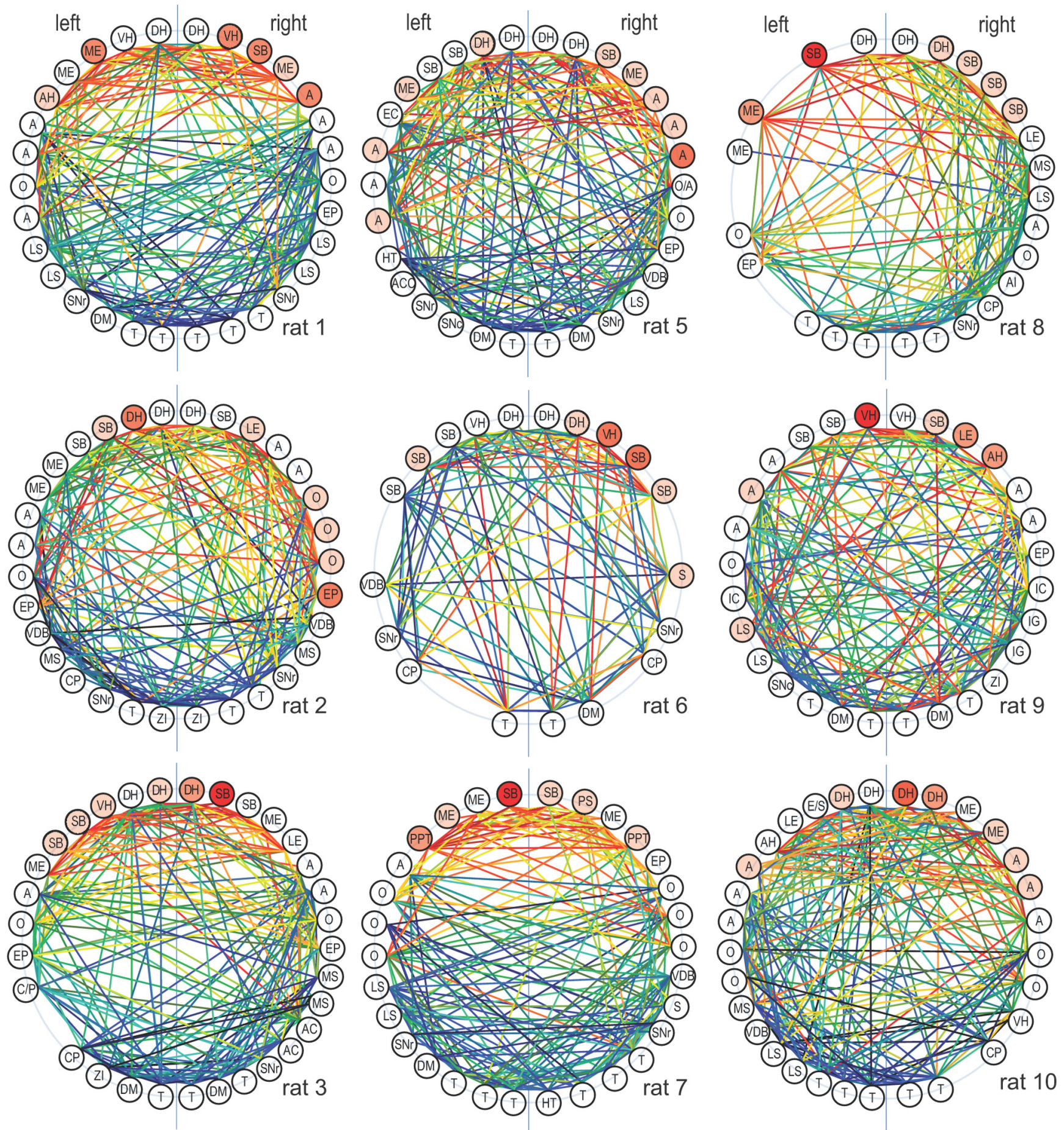

Figure 6. Sites of seizure initiation and patterns of spread among recorded structures. Plots of earliest seizure recording and patterns of spread for the other nine rats (10 seizures/rat). The right hemisphere was more likely than the left to show earliest seizure activity in rat nos. 6 and $10(p<0.05, t$ test). A indicates amygdala; $\mathrm{AC}$, anterior cingulate cortex; $\mathrm{ACC}$, nucleus accumbens; $\mathrm{AH}$, amygdalo-hippocampus; Al, agranular insular cortex; $\mathrm{CP}$, cerebral peduncle; C/P, caudate/putamen; DH, dorsal hippocampus; DM, dorsomedial thalamus; EC, entorhinal cortex; EP, endopiriform nucleus; E/S, entorhinal-subiculum transition area; $\mathrm{HT}$, hypothalamus; IC, insular cortex; IG, indusium griseum; LE, lateral entorhinal cortex; LS, lateral septum; ME, medial entorhinal cortex; MS, medial septum; 0, olfactory cortex; 0/A, olfactory cortex-amygdala transition area; PPT, postpiriform transition area; PS, parasubiculum; S, septum; SB, subiculum; SNc, substantia nigra pars compacta; $\mathrm{SNr}$, substantia nigra pars reticulata; T, nondorsomedial thalamus; VDB, ventral diagonal band; VH, ventral hippocampus; Zl, zona incerta.

\footnotetext{
(Figure legend continued.) of earliest recorded seizure onsets indicated by darkness of circle. Warm- and cold-colored lines tend to be located separately, indicating nonrandom patterns in seizure spread. The right hemisphere was more likely than the left to show earliest seizure activity $(p<0.05$, $t$ test). A indicates amygdala; DH, dorsal hippocampus; $\mathrm{EP}$, endopiriform nucleus; $\mathrm{LHT}$, lateral hypothalamus; $L S$, lateral septum; MS, medial septum; 0 , olfactory cortex; SB, Subiculum; SNr, substantia nigra pars reticulata; T, nondorsomedial thalamus; Zl, zona incerta.
}

activity to spread from one hemisphere to the other in rats was $2.1 \pm$ $0.4 \mathrm{~s}$ (median, $0.9 \mathrm{~s}$; range, $0.002-15.5 \mathrm{~s}$ ). Interhemispheric propagation times for patients with temporal lobe epilepsy tend to be $>10$ times longer (Lieb et al., 1976; Spencer et al., 1990, 1992; Spanedda et al., 1997). These findings reveal that, compared with patients, seizures spread more rapidly in epileptic pilocarpine-treated rats. 

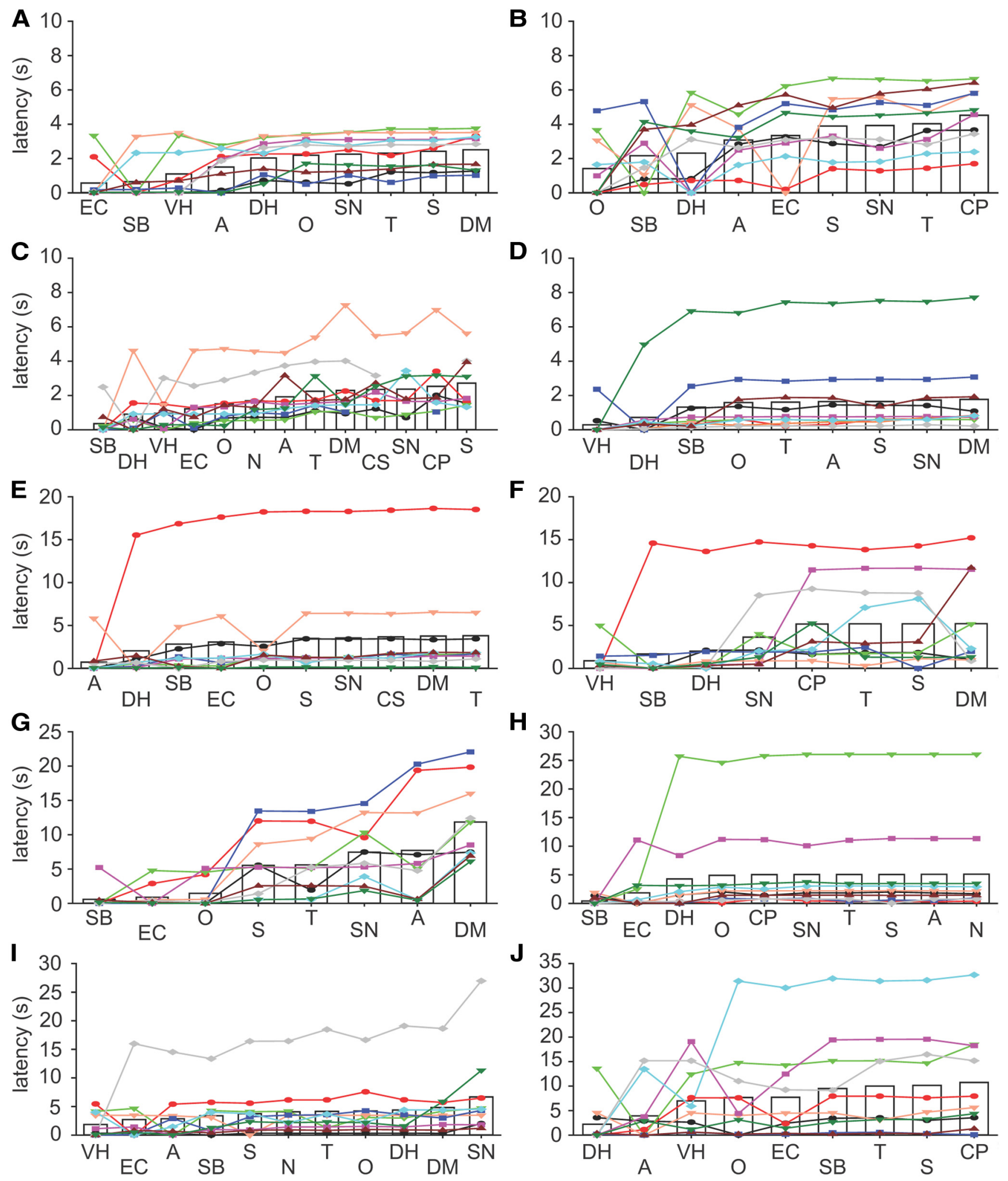

Figure 7. Seizure onset latencies by brain regions of individual rats. $A-J$, Earliest onset latencies for each seizure (line-scatter plots) and averages of 10 seizures (bars) for rat nos. 1-10. Note differences in $y$-axis scales. A indicates amygdala; $\mathrm{CP}$, cerebral peduncle; $\mathrm{CS}$, corpus striatum; DH, dorsal hippocampus; DM, dorsomedial thalamus; EC, entorhinal cortex; N, neocortex; 0 , olfactory cortex; $\mathrm{S}$, septum; SB, subiculum; SN, substantia nigra; $T$, nondorsomedial thalamus; $V \mathrm{VH}$, ventral hippocampus.

\section{Seizure onset sites}

Sites of earliest recorded seizure activity might be where seizures initiate. Results were evaluated to determine whether seizure characteristics vary with respect to where they might initiate.
Seizures were detected as the earliest of four methods (by-eye, slow-wave, and peak spectral power at $20-200$ or $200-600 \mathrm{~Hz}$ ). For each region, the percentage of earliest seizure onsets detected by each method was plotted (Fig. 9A). Earliest seizure activity was detected by multiple markers in all seizure onset regions except 
the septum, in which only two seizure onsets were recorded. Earliest seizure activity was most frequently detected by eye in the hippocampal formation (dorsal and ventral hippocampus, entorhinal cortex, and subiculum) and by the slow wave in other regions (amygdala, olfactory cortex, and septum). There were no significant differences in seizure duration or latency of seizure spread (see below) with respect to seizure onset markers (ANOVA on ranks with Dunn's method).

Seizure onset sites had no significant effect on whether seizures were convulsive or not and whether seizures began during sleep versus wakefulness ( $\chi^{2}$ tests). Most seizures were convulsive regardless of the potential onset site (Fig. 9B). For 61/100 seizures, video recordings were sufficient to determine whether rats were awake (eyes open with or without movement, $n=22$ ) or probably asleep (resting and eyes closed, $n=39$ ). Most seizures began when rats probably were asleep regardless of the potential onset site except the olfactory cortex, in which half of the seizures began when rats were awake and half when asleep, and the septum, in which only one seizure was available for analysis (Fig. 9C). There was no significant correlation between sleep/wake state and whether seizures were convulsive ( $\chi^{2}$ test).

The time it took for seizures to spread was measured as the latency of onsets from the earliest recorded region to the last. Average seizure latency was 4.5-10.3 s at all seizure onset sites (Fig. 9D). There was no significant difference between sites (ANOVA on ranks). Average seizure latency for convulsive seizures $(6.8 \pm 0.8 \mathrm{~s}$, $n=66$ ) was similar to that of nonconvulsive seizures ( $7.4 \pm 1.2 \mathrm{~s}, n=34, p=0.65$, $t$ test).

\section{Neuropathology}

Qualitative evaluation of Nissl-stained sections revealed similar neuropathological changes in pilocarpine-treated rats of the present study with those reported previously for epileptic kainate-treated rats (Chen and Buckmaster, 2005). Hilar neuron loss was a consistent abnormality, although its extent was variable. Neuron loss in other brain regions was sometimes evident in the amygdala, olfactory cortex, and thalamus. There was no obvious correlation between areas of neuron loss and sites of earliest seizure activity. For example, seizures frequently were recorded earliest in the subiculum, but the subiculum displayed little if any evidence of damage (Fig. 1A). Another example is rat no. 5 , in
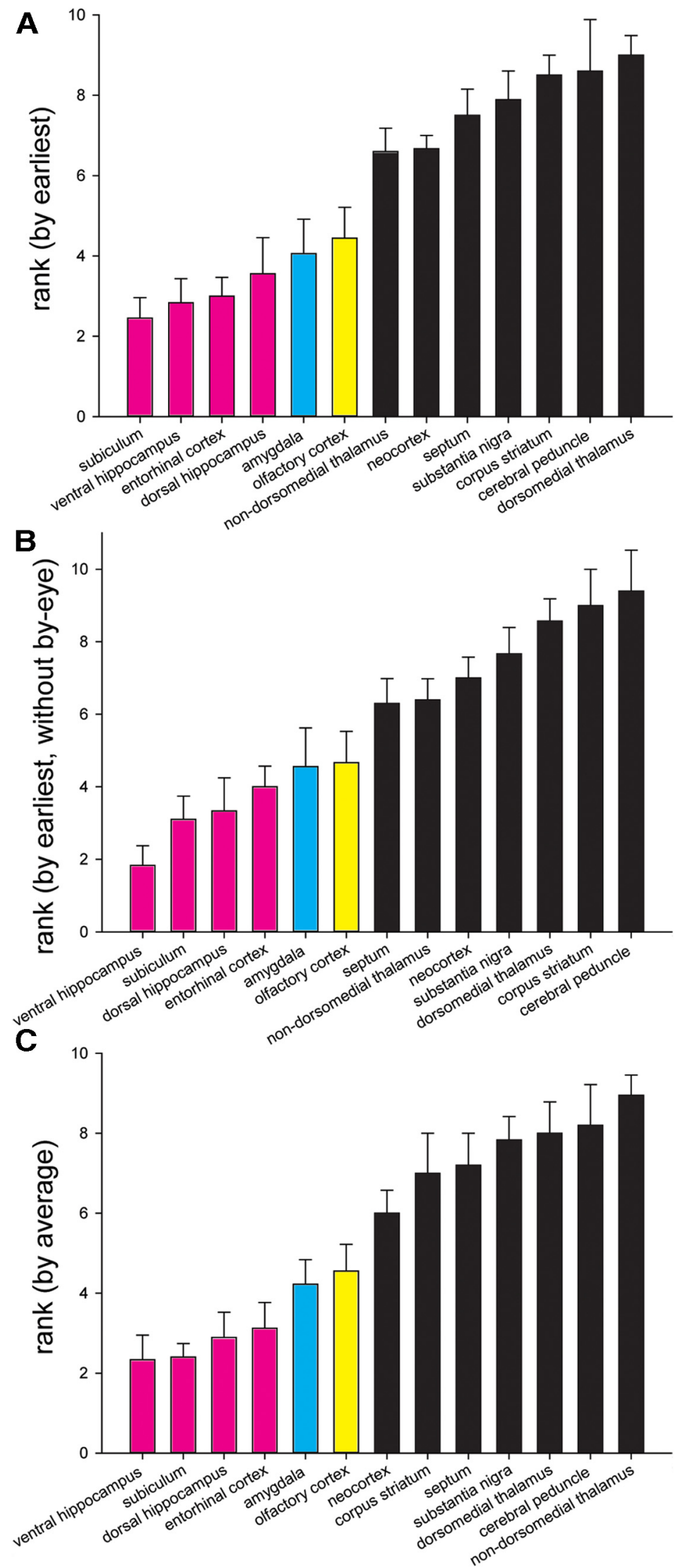

Figure 8. Seizure onset latency ranks by brain regions. $A$, Earliest onset latencies ranked and then averaged across 10 rats. Bars indicate SEM. Parts of the hippocampal formation (magenta), amygdala (blue), and olfactory cortex (yellow) are indicated by color. $\boldsymbol{B}$, Earliest latencies ranked without by-eye measurements of seizure onset. $\boldsymbol{C}$, Similar to data in $\boldsymbol{A}$ except onset latencies were determined by the average instead of the earliest value for all electrodes in each brain region. 
Table 2. Brain regions of individually identified rats tested for early or late seizure onset latency

\begin{tabular}{|c|c|c|c|c|c|c|c|c|c|c|c|c|}
\hline rat & 1 & 2 & 3 & 4 & 5 & 6 & 7 & 8 & 9 & 10 & early & late \\
\hline subiculum & & & & & & & & & & & $90 \%$ & $0 \%$ \\
\hline $\begin{array}{l}\text { ventral } \\
\text { hippocampus }\end{array}$ & & $n / a$ & & & $n / a$ & & $n / a$ & $n / a$ & & & $83 \%$ & $0 \%$ \\
\hline $\begin{array}{l}\text { entorhinal } \\
\text { cortex }\end{array}$ & & & & $\mathrm{n} / \mathrm{a}$ & & $\mathrm{n} / \mathrm{a}$ & & & & & $88 \%$ & $0 \%$ \\
\hline $\begin{array}{l}\text { dorsal } \\
\text { hippocampus }\end{array}$ & & & & & & & $\mathrm{n} / \mathrm{a}$ & & & & $67 \%$ & $11 \%$ \\
\hline amygdala & & & & & & $\mathrm{n} / \mathrm{a}$ & & & & & $56 \%$ & $33 \%$ \\
\hline $\begin{array}{l}\text { olfactory } \\
\text { cortex }\end{array}$ & & & & & & $\mathrm{n} / \mathrm{a}$ & & & & & $33 \%$ & $11 \%$ \\
\hline $\begin{array}{l}\text { non- } \\
\text { dorsomedial } \\
\text { thalamus }\end{array}$ & & & & & & & & & & & $10 \%$ & $70 \%$ \\
\hline neocortex & $\mathrm{n} / \mathrm{a}$ & $\mathrm{n} / \mathrm{a}$ & & $\mathrm{n} / \mathrm{a}$ & $n / a$ & $\mathrm{n} / \mathrm{a}$ & $\mathrm{n} / \mathrm{a}$ & & & $\mathrm{n} / \mathrm{a}$ & $0 \%$ & $33 \%$ \\
\hline septum & & & & & & & & & & & $10 \%$ & $70 \%$ \\
\hline $\begin{array}{l}\text { dorsomedial } \\
\text { thalamus }\end{array}$ & & $n / a$ & & & & & & $\mathrm{n} / \mathrm{a}$ & & $\mathrm{n} / \mathrm{a}$ & $0 \%$ & $86 \%$ \\
\hline $\begin{array}{l}\text { substantia } \\
\text { nigra }\end{array}$ & & & & & & & & & & $\mathrm{n} / \mathrm{a}$ & $0 \%$ & $100 \%$ \\
\hline $\begin{array}{l}\text { corpus } \\
\text { striatum }\end{array}$ & $\mathrm{n} / \mathrm{a}$ & $\mathrm{n} / \mathrm{a}$ & & $n / a$ & & $\mathrm{n} / \mathrm{a}$ & $\mathrm{n} / \mathrm{a}$ & $n / a$ & $\mathrm{n} / \mathrm{a}$ & $\mathrm{n} / \mathrm{a}$ & $0 \%$ & $100 \%$ \\
\hline $\begin{array}{l}\text { cerebral } \\
\text { peduncle }\end{array}$ & $\mathrm{n} / \mathrm{a}$ & & & $\mathrm{n} / \mathrm{a}$ & $\mathrm{n} / \mathrm{a}$ & & $\mathrm{n} / \mathrm{a}$ & & $\mathrm{n} / \mathrm{a}$ & & $0 \%$ & $100 \%$ \\
\hline
\end{tabular}

Friedman repeated-measures ANOVA on ranks with Tukey post hoc comparisons was used. Red indicates that the region had a significantly shorter seizure onset latency than at least one other region in that rat. Blue indicates that the region had a significantly longer seizure onset latency than at least one other region in that rat. n/a indicates structures not recorded.

which seizures were frequently recorded first in the right amygdala, which looked relatively normal (Fig. 1B).

\section{Discussion}

Results of the present study reveal similarities and differences of spontaneous seizures in the commonly used pilocarpine-treated rat model compared with those reported for patients with temporal lobe epilepsy. Differences include the following: in rats, seizures tend to be shorter, spread faster, involve more brain regions, generate behavioral manifestations more quickly, and develop into generalized convulsions more frequently. Similarities include the following: waveform patterns of electrographic seizure onset, variability within individuals in sites of earliest seizure activity and in sequences of seizure spread among brain regions, and earliest seizure activity is recorded most frequently within the hippocampal formation, especially its temporal region.
Validity of the pilocarpine-treated rat model of temporal lobe epilepsy

Results of the present study suggest that seizures initiate in the hippocampal formation of pilocarpine-treated rats, which contrasts with previous studies questioning the validity of the model. Mello et al. (1996) evaluated fos immunoreactivity in pilocarpinetreated rats and speculated that spontaneous seizures result from initial activation of area tempestas or limbic structures other than the hippocampus proper. Area tempestas is within or near the endopiriform nucleus (Piredda and Gale, 1985). In the present study, the endopiriform nucleus, which was included in the broader olfactory cortical region, contained at least one recording electrode in 7/10 rats, but in only one was the earliest seizure activity recorded there. The broader olfactory cortical region occupies a proportionally large fraction of the rat forebrain and is the most severely atrophied region in kainate-treated rats (Chen and Buckmaster, 2005). Nevertheless, it displayed earliest seizure 

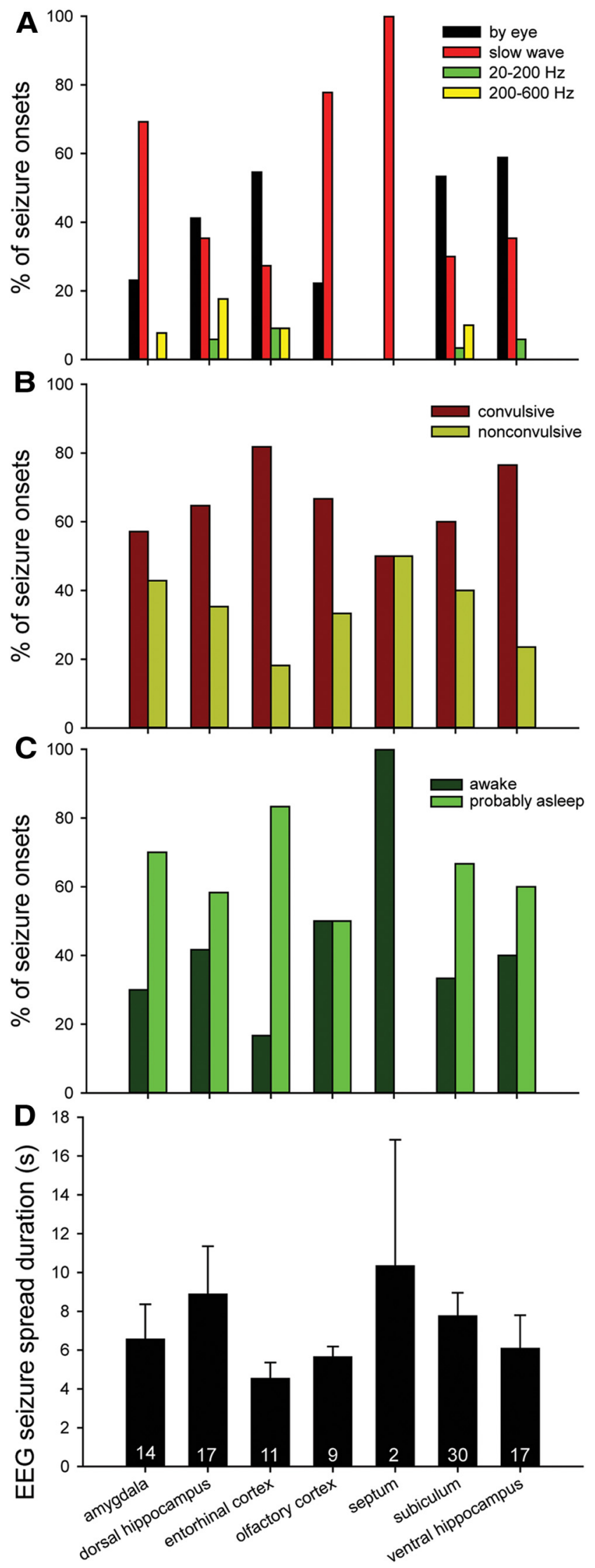

Figure 9. Sites of earliest recorded seizure activity versus parameters of seizure onset, behavior, and spread. $\boldsymbol{A}$, Percentage of seizure onsets detected by each marker (by eye, slow wave, or peak of spectral power at $20-200$ or $200-600 \mathrm{~Hz}$ ) for each region where seizures were recorded earliest. For example, of the 17 seizures with earliest activity in the dorsal hippocampus, activity only occasionally and not more often than expected by chance. Limbic structures other than the hippocampus proper, including the amygdala occasionally and the subiculum and entorhinal cortex more frequently, displayed earliest seizure activity in pilocarpine-treated rats. However, contrary to the prediction of Mello et al. (1996), the hippocampus proper frequently displayed earliest seizure activity. Limitations of using fos immunoreactivity to identify sites of early seizure activity might account for the different conclusions. Harvey and Sloviter (2005) also used fos immunoreactivity, but added video and local field potential recording to evaluate epileptic pilocarpine-treated rats. They concluded that spontaneous seizures were probably of extrahippocampal origin, although the site was not identified, and they challenged the validity of the model. Their definition of seizure activity required the paroxysmal onset of population spikes instead of more conventional waveforms that are typically used to identify seizure onset in patients with temporal lobe epilepsy (Engel, 1990; Spencer et al., 1990, 1992; Brekelmans et al., 1995; Velasco et al., 2000; Weinand et al., 2007; Götz-Trabert et al., 2008; Ogren et al., 2009) and in rodent models (Mathern et al., 1993; Bertram, 1997; Bragin et al., 1999, 2005; Lévesque et al., 2012). The population spike criterion of Harvey and Sloviter (2005) pushed electrographic seizure onsets later than behavioral onsets. However, in pilocarpine-treated rats, granule cell unit activity increases significantly and abruptly before population spikes develop in epileptic discharges (Bower and Buckmaster, 2008). The present study used conventional seizure onset criteria and revealed the frequent early involvement of the hippocampal formation, with electrographic onsets almost always preceding behavioral onsets.

Earliest seizure activity was most likely to be recorded in the ventral region of the hippocampus, which is homologous to the anterior hippocampus in humans. The anterior hippocampus is more epileptogenic (King and Ajmone Marsan, 1977; Masukawa et al., 1995; King et al., 1997), displays more severe neuropathological changes (Mouritzen Dam, 1980; Babb et al., 1984), and is the part of the hippocampus resected to treat patients with temporal lobe epilepsy. In the present study, the ventral subiculum was recorded and frequently displayed early seizure activity. The ventral subiculum allows spread of seizure activity (Kliot and Poletti, 1979) and supports seizure generation in patients with temporal lobe epilepsy (Huberfeld et al., 2011). The amygdala is located adjacent to the temporal end of the hippocampus. In patients with temporal lobe epilepsy, the amygdala is second only to the hippocampal formation in seizure initiation (Quesney, 1986; Spanedda et al., 1997; Wennberg et al., 2002), and the same was found in pilocarpine-treated rats. Therefore, patients with temporal lobe epilepsy and pilocarpine-treated rats have common sites of likely seizure initiation, which supports the model's validity. However, there is a caveat regarding seizure onset iden-

\footnotetext{
7 (41\%) were detected by eye, $6(35 \%)$ by a slow wave, $1(6 \%)$ by peak of spectral power at $20-200 \mathrm{~Hz}$, and $3(18 \%)$ at $200-600 \mathrm{~Hz}$. B. Percentage of seizure onsets that were convulsive versus nonconvulsive for each region where seizures were recorded earliest. C, Percentage of seizure onsets that occurred during wakefulness versus probable sleep for each region where seizures were recorded earliest. Video recording was sufficient to analyze only a subset of seizures for which earliest activity was recorded first in the amygdala (10), dorsal hippocampus (12), entorhinal cortex (6), olfactory cortex (4), septum (1), subiculum (18), and ventral hippocampus (10). $\boldsymbol{D}$, Latency of seizure spread measured from the onset of the first to the onset of the last region for each seizure. Values represent mean \pm SEM. Number of seizures are indicated, which also pertains to graphs in $\boldsymbol{A}$ and $\boldsymbol{B}$.
} 
tification. The local field potential recording technique used in the present study provided high temporal resolution but constrained spatial resolution. Each wire electrode detects local field potentials within a volume that might be as small as $0.07 \mathrm{~mm}^{3}$ (Katzner et al., 2009; Xing et al., 2009; but see Kajikawa and Schroeder, 2011). Rat brains have a total volume of $2000 \mathrm{~mm}^{3}$ (Swanson, 1992); therefore, 32 electrodes might record the activity of only $0.1 \%$ of a rat's brain. Therefore, limits of the approach make it impossible to exclude the possibility of seizure activity initiating even earlier at sites not recorded. For example, in patients, seizures sometimes initiate in the neocortex of the lateral temporal lobe (Quesney, 1986; Spencer et al., 1990). The present study included data from five electrodes placed in the neocortex, including the insula, of three rats. In none of those cases was earliest seizure activity recorded. However, more work is needed to determine whether seizures in rodent models begin in regions homologous to the human lateral temporal neocortex.

\section{Brain regions probably not commonly involved in seizure initiation}

Some brain regions that had been hypothesized to contribute to the initiation and spread of spontaneous seizures were tested by measuring their onset latencies. The thalamus (Margerison and Corsellis, 1966; DeCarli et al., 1998), especially the dorsomedial region, displays abnormalities in patients with temporal lobe epilepsy (Juhász et al., 1999) and in rodent models (Bertram et al., 2001). The dorsomedial thalamus has been proposed to play a critical role in the development of limbic seizures (Bertram et al., 1998, 2008; Cassidy and Gale, 1998; Blumenfeld et al., 2007). In the present study, 10 electrodes in seven rats were implanted in the dorsomedial thalamus. The substantia nigra, especially pars reticulata, displays neuropathological abnormalities in pilocarpine-treated rats (Turski et al., 1986; Schmidt-Kastner et al., 1991). The substantia nigra is activated during seizures (Lothman and Collins, 1981), especially when they generalize (Engel et al., 1978). In the present study, $13 / 15$ electrodes in the substantia nigra of nine rats were in pars reticulata. The septum is atrophied in rodent models (Chen and Buckmaster, 2005), including pilocarpine-treated rats (Turski et al., 1986; Correia et al., 1998; Garrido Sanabria et al., 2006), and it has been proposed to participate in seizure initiation (Popava et al., 2008). All of the rats in the present study had electrodes implanted in the septum. However, despite abundant sampling, the septum, substantia nigra, and dorsomedial thalamus had significantly late seizure onsets in pilocarpine-treated rats, suggesting that these brain regions are probably not important for the initiation of spontaneous seizures in this model.

\section{Limitations of the pilocarpine-treated rat model of temporal lobe epilepsy}

Converging data from the present study suggest that seizures spread faster and more extensively in pilocarpine-treated rats than in patients with temporal lobe epilepsy. On average, it took $<3$ s for seizures to spread to the contralateral hemisphere and $<7 \mathrm{~s}$ for them to spread to all recorded brain regions in pilocarpine-treated rats. In $95 \%$ of the cases, seizure activity was detected at all recorded brain regions. Additional evidence of fast and extensive seizure spread includes average behavioral seizure onset latency $<8 \mathrm{~s}$ and $>75 \%$ of seizures causing generalized convulsions.

The reason for the faster and more extensive seizure spread in rats is unclear, but there are several possibilities. In rats, systemic administration of convulsants to induce status epilepticus causes bilateral neuropathological damage. In contrast, many patients with temporal lobe epilepsy have unilateral or asymmetric lesions (Margerison and Corsellis, 1966). Bilateral damage in rats might facilitate seizure spread. Furthermore, extrahippocampal damage appears to be more severe in chemoconvulsant rodent models than in patients with temporal lobe epilepsy (Chen and Buckmaster, 2005). Seizure spread also might be facilitated by hippocampal commissural fiber tracts, which are more developed in rodents (Fernandes de Lima et al., 1990) than in primates (Amaral et al., 1984; Demeter et al., 1985). Brain size also might contribute to interspecies differences in seizure propagation. Human brains are 700 times larger than rat brains and seizure spread might take longer in humans because brain regions are farther apart. Despite the larger human brain, which is composed of many more neurons, the average number of synapses received by individual neurons is approximately similar to that of rodents (DeFelipe et al., 2002). If there are more neurons but a similar number of synapses per neuron, then human brains are not simply scaled-up versions of smaller brains. Instead, on average, neurons in human brains must be less interconnected. Reduced connectivity may delay and limit seizure spread in humans compared with rodents.

\section{References}

Afra P, Jouny CC, Bergey GK (2008) Duration of complex partial seizures: an intracranial EEG study. Epilepsia 49:677-684. CrossRef Medline

Amaral DG, Insausti R, Cowan WM (1984) The commissural connections of the monkey hippocampal formation. J Comp Neurol 224:307-336. CrossRef Medline

Babb TL, Brown WJ, Pretorius J, Davenport C, Lieb JP, Crandall PH (1984) Temporal lobe volumetric cell densities in temporal lobe epilepsy. Epilepsia 25:729-740. CrossRef Medline

Bertram EH (1997) Functional anatomy of spontaneous seizures in a rat model of limbic epilepsy. Epilepsia 38:95-105. CrossRef Medline

Bertram EH, Zhang DX, Mangan P, Fountain N, Rempe D (1998) Functional anatomy of limbic epilepsy: a proposal for central synchronization of a diffusely hyperexcitable network. Epilepsy Res 32:194-205. CrossRef Medline

Bertram EH, Mangan PS, Zhang D, Scott CA, Williamson JM (2001) The midline thalamus: alterations and a potential role in limbic epilepsy. Epilepsia 42:967-978. CrossRef Medline

Bertram EH, Zhang D, Williamson JM (2008) Multiple roles of midline dorsal thalamic nuclei in induction and spread of limbic seizures. Epilepsia 49:256-268. CrossRef Medline

Blumenfeld H, Rivera M, Vasquez JG, Shah A, Ismail D, Enev M, Zaveri HP (2007) Neocortical and thalamic spread of amygdala kindled seizures. Epilepsia 48:254-262. CrossRef Medline

Bower MR, Buckmaster PS (2008) Changes in granule cell firing rates precede locally recorded spontaneous seizures by minutes in an animal model of temporal lobe epilepsy. J Neurophysiol 99:2431-2442. CrossRef Medline

Bragin A, Engel J Jr, Wilson CL, Vizentin E, Mathern GW (1999) Electrophysiologic analysis of a chronic seizure model after unilateral hippocampal KA injection. Epilepsia 40:1210-1221. CrossRef Medline

Bragin A, Azizyan A, Almajano J, Wilson CL, Engel J Jr (2005) Analysis of chronic seizure onsets after intrahippocampal kainic acid injection in freely moving rats. Epilepsia 46:1592-1598. CrossRef Medline

Brekelmans GJF, van Emde Boas W, Velis DN, van Huffelen AC, Debets RMC, van Veelen CWM (1995) Mesial temporal versus neocortical temporal lobe seizures: demonstration of different electroencephalographic spreading patterns by combined use of subdural and intracerebral electrodes. Journal of Epilepsy 8:309-320. CrossRef

Buckmaster PS (2004) Laboratory animal models of temporal lobe epilepsy. Comp Med 54:473-485. Medline

Cassidy RM, Gale K (1998) Mediodorsal thalamus plays a critical role in the development of limbic motor seizures. J Neurosci 18:9002-9009. Medline

Cavanagh JB, Meyer A (1956) Aetiological aspects of Ammon's horn sclerosis associated with temporal lobe epilepsy. Br Med J 2:1403-1407. CrossRef Medline 
Chen S, Buckmaster PS (2005) Stereological analysis of forebrain regions in kainate-treated epileptic rats. Brain Res 1057:141-152. CrossRef Medline

Correia L, Amado D, Cavalheiro EA, Bentivoglio M (1998) Persistence and atrophy of septal/diagonal band neurons expressing the p75 neurotrophin receptor in pilocarpine-induced chronic epilepsy in the rat. Brain Res 809:288-293. CrossRef Medline

DeCarli C, Hatta J, Fazilat S, Fazilat S, Gaillard WD, Theodore WH (1998) Extratemporal atrophy in patients with complex partial seizures of left temporal origin. Ann Neurol 43:41-45. CrossRef Medline

DeFelipe J, Alonso-Nanclares L, Arellano JI (2002) Microstructure of the neocortex: comparative aspects. J Neurocytol 31:299-316. CrossRef Medline

Demeter S, Rosene DL, Van Hoesen GW (1985) Interhemispheric pathways of the hippocampal formation, presubiculum, and entorhinal and posterior parahippocampal cortices in the rhesus monkey: the structure and organization of the hippocampal commissures. J Comp Neurol 233:30-47. CrossRef Medline

Du F, Whetsell WO Jr, Abou-Khalil B, Blumenkopf B, Lothman EW, Schwarcz R (1993) Preferential neuronal loss in layer III of the entorhinal cortex in patients with temporal lobe epilepsy. Epilepsy Res 16:223233. CrossRef Medline

Duckrow RB, Spencer SS (1992) Regional coherence and the transfer of ictal activity during seizure onset in the medial temporal lobe. Electroencephalogr Clin Neurophysiol 82:415-422. CrossRef Medline

Engel J Jr (1990) Functional explorations of the human epileptic brain and their therapeutic implications. Electroencephalogr Clin Neurophysiol 76: 296-316. CrossRef Medline

Engel J Jr, Williamson PD, Wieser H-G (1997) Mesial temporal lobe epilepsy. In: Epilepsy: a comprehensive textbook (Engel J Jr, Pedley TA, eds) Philadelphia: Lippincott-Raven, pp 2417-2426.

Engel J Jr, Wolfson L, Brown L (1978) Anatomical correlates of electrical and behavioral events related to amygadaloid kindling. Ann Neurol 3:538-544. CrossRef Medline

Falconer MA, Serafetinides EA, Corsellis JAN (1964) Etiology and pathogenesis of temporal lobe epilepsy. Arch Neurol 10:233-248. CrossRef Medline

Fernandes de Lima VM, Pijn JP, Nunes Filipe C, Lopes da Silva F (1990) The role of hippocampal commissures in the interhemispheric transfer of epileptiform afterdischarges in the rat: a study using linear and non-linear regression analysis. Electroencephalogr Clin Neurophysiol 76:520-539. CrossRef Medline

French JA, Williamson PD, Thadani VM, Darcey TM, Mattson RH, Spencer SS, Spencer DD (1993) Characteristics of medial temporal lobe epilepsy: I. Results of history and physical examination. Ann Neurol 34:774-780. CrossRef Medline

Garrido Sanabria ER, Castañeda MT, Banuelos C, Perez-Cordova MG, Hernandez S, Colom LV (2006) Septal GABAergic neurons are selectively vulnerable to pilocarpine-induced status epilepticus and chronic spontaneous seizures. Neuroscience 142:871-883. CrossRef Medline

Götz-Trabert K, Hauck C, Wagner K, Fauser S, Schulze-Bonhage A (2008) Spread of ictal activity in focal epilepsy. Epilepsia 29:1594-1601. CrossRef. Medline

Harvey BD, Sloviter RS (2005) Hippocampal granule cell activity and c-Fos expression during spontaneous seizure in awake, chronically epileptic, pilocarpine-treated rats: implications for hippocampal epileptogenesis. J Comp Neurol 488:442-463. CrossRef Medline

Huberfeld G, Menendez de la Prida L, Pallud J, Cohen I, Le Van Quyen M, Adam C, Clemenceau S, Baulac M, Miles R (2011) Glutamatergic preictal discharges emerge at the transition to seizure in human epilepsy. Nat Neurosci 14:627-634. CrossRef Medline

Institute of Medicine (US) Committee on the Public Health Dimensions of the Epilepsies; England MJ, Liverman CT, Schultz AM, Strawbridge LM, editors (2012) Epilepsy across the spectrum: promoting health and understanding. Washington DC: The National Academics, p. 1. Medline

Juhász C, Nagy F, Watson C, da Silva EA, Muzik O, Chugani DC, Shah J, Chugani HT (1999) Glucose and $\left[{ }^{11} \mathrm{C}\right]$ flumazenil positron emission tomography abnormalities of thalamic nuclei in temporal lobe epilepsy. Neurology 53:2037-2045. CrossRef Medline

Kajikawa Y, Schroeder CE (2011) How local is the local field potential? Neuron 72:847-858. CrossRef Medline

Katzner S, Nauhaus I, Benucci A, Bonin V, Ringach DL, Carandini M (2009)
Local origin of field potentials in visual cortex. Neuron 61:35-41. CrossRef Medline

King DW, Ajmone Marsan C (1977) Clinical features and ictal patterns in epileptic patients with EEG temporal lobe foci. Ann Neurol 2:138-147. CrossRef

King D, Bronen RA, Spencer DD, Spencer SS (1997) Topographic distribution of seizure onset and hippocampal atrophy: relationship between MRI and depth EEG. Electroencephalogr Clin Neurophysiol 103:692-697. CrossRef Medline

Kliot M, Poletti CE (1979) Hippocampal afterdischarges: differential spread of activity shown by the $\left[{ }^{14} \mathrm{C}\right]$ deoxyglucose technique. Science 204:641-643. CrossRef Medline

Kramer MA, Truccolo W, Eden UT, Lepage KQ, Hochberg LR, Eskandar EN, Madsen JR, Lee JW, Maheshwari A, Halgren E, Chu CJ, Cash SS (2012) Human seizures self-terminate across spatial scales via a critical transition. Proc Natl Acad Sci U S A 109:21116-21121. CrossRef Medline

Lévesque M, Salami P, Gotman J, Avoli M (2012) Two seizure-onset types reveal specific patterns of high-frequency oscillations in a model of temporal lobe epilepsy. J Neurosci 32:13264-13272. CrossRef Medline

Lieb JP, Walsh GO, Babb TL, Walter RD, Crandall PH (1976) A comparison of EEG seizure patterns recorded with surface and depth electrodes in patients with temporal lobe epilepsy. Epilepsia 17:137-160. CrossRef Medline

Lothman EW, Collins RC (1981) Kainic acid induced limbic seizures: metabolic, behavioral, electroencephalographic and neuropathological correlates. Brain Res 218:299-318. CrossRef Medline

Lowenstein DH (2011) Interview: the National Institute of Neurological Diseases and Stroke/American Epilepsy Society benchmarks and research priorities for epilepsy research. Biomarkers Med 5:531-535. CrossRef Medline

Margerison JH, Corsellis JA (1966) Epilepsy and the temporal lobes. Brain 89:499-530. CrossRef Medline

Martin BS, Kapur J (2008) A combination of ketamine and diazepam synergistically controls refractory status epilepticus induced by cholinergic stimulation. Epilepsia 49:248-255. CrossRef Medline

Masukawa LM, O'Connor WM, Lynott J, Burdette LJ, Uruno K, McGonigle P, O’Connor MJ (1995) Longitudinal variation in cell density and mossy fiber reorganization in the dentate gyrus from temporal lobe epilepsy patients. Brain Res 678:65-75. CrossRef Medline

Mathern GW, Cifuentes F, Leite JP, Pretorius JK, Babb TL (1993) Hippocampal EEG excitability and chronic spontaneous seizures are associated with aberrant synaptic reorganization in the rat intrahippocampal kainate model. Electroencephalogr Clin Neurophysiol 87:326-339. CrossRef Medline

Mello LE, Kohman CM, Tan AM, Cavalheiro EA, Finch DM (1996) Lack of Fos-like immunoreactivity after spontaneous seizures or reinduction of status epilepticus by pilocarpine in rats. Neurosci Lett 208:133-137. CrossRef Medline

Dam AM (1980) Epilepsy and neuron loss in the hippocampus. Epilepsia 21:617-629. CrossRef Medline

Ogren JA, Bragin A, Wilson CL, Hoftman GD, Lin JJ, Dutton RA, Fields TA, Toga AW, Thompson PM, Engel J Jr, Staba RJ (2009) Threedimensional hippocampal atrophy maps distinguish two common temporal lobe seizure-onset patterns. Epilepsia 50:1361-1370. CrossRef Medline

Piredda S, Gale K (1985) A crucial epileptogenic site in the deep prepiriform cortex. Nature 317:623-625. CrossRef Medline

Popova IY, Sinelnikova VV, Kitchigina VF (2008) Disturbance of the correlation between hippocampal and septal EEGs during epileptogenesis. Neurosci Lett 442:228-233. CrossRef Medline

Quesney LF (1986) Clinical and EEG features of complex partial seizures of temporal lobe origin. Epilepsia 27:S27-S45. Medline

Racine RJ (1972) Modification of seizure activity by electrical stimulation. II. Motor seizure. Electroencephalogr Clin Neurophysiol 32:281-294. CrossRef Medline

Sano K, Malamud N (1953) Clinical significance of sclerosis of the cornu ammonis. Arch Neurol Psychiatry 70:40-53. CrossRef Medline

Schmidt-Kastner R, Heim C, Sontag KH (1991) Damage of substantia nigra pars reticulata during pilocarpine-induced status epilepticus in the rat: Immunohistochemical study of neurons, astrocytes and serum-protein extravasation. Exp Brain Res 86:125-140. Medline 
Scholz W (1959) The contribution of patho-anatomical research to the problem of epilepsy. Epilepsia 1:36-55. CrossRef

Sloviter RS, Zappone CA, Bumanglag AV, Borwood BA, Kudrimoti H (2007) On the relevance of prolonged convulsive status epilepticus to the etiology and neurobiology of human temporal lobe epilepsy. Epilepsia 48:6-10. Medline

Spanedda F, Cendes F, Gotman J (1997) Relations between EEG seizure morphology, interhemispheric spread, and mesial temporal atrophy in bitemporal epilepsy. Epilepsia 38:1300-1314. CrossRef Medline

Spencer SS (1998) Substrates of localization-related epilepsies: biologic implications of localizing findings in humans. Epilepsia 39:114-123. CrossRef Medline

Spencer SS (2002) Neural networks in human epilepsy: evidence of and implications for treatment. Epilepsia 43:219-227. CrossRef Medline

Spencer SS, Spencer DD (1994) Entorhinal-hippocampal interactions in medial temporal lobe epilepsy. Epilepsia 35:721-727. CrossRef Medline

Spencer SS, Williamson PD, Spencer DD, Mattson RH (1987) Human hippocampal seizure spread studied by depth and subdural recording: the hippocampal commissure. Epilepsia 28:479-489. CrossRef Medline

Spencer SS, Spencer DD, Williamson PD, Mattson R (1990) Combined depth and subdural electrode investigation in uncontrolled epilepsy. Neurology 40:74-79. CrossRef Medline

Spencer SS, Marks D, Katz A, Kim J, Spencer DD (1992) Anatomic correlates of interhippocampal seizure propagation time. Epilepsia 33:862-873. CrossRef Medline

Spencer SS, Kim J, de Lanerolle N, Spencer DD (1999) Differential neuronal and glial relations with parameters of ictal discharge in mesial temporal lobe epilepsy. Epilepsia 40:708-712. CrossRef Medline

Sperling MR, O'Connor MJ (1989) Comparison of depth and subdural electrodes in recording temporal lobe seizures. Neurology 39:1497-1504. CrossRef Medline
Sperling MR, O'Connor MJ (1990) Auras and subclinical seizures: characteristics and prognostic significance. Ann Neurol 28:320-328. CrossRef Medline

Swanson LW (1992) Brain maps: structure of the rat brain, p 7. New York, Elsevier.

Turski L, Cavalheiro EA, Sieklucka-Dziuba M, Ikonomidou-Turski C, Czuczwar SJ, Turski WA (1986) Seizures produced by pilocarpine: neuropathological sequelae and activity of glutamate decarboxylase in the rat forebrain. Brain Res 398:37-48. CrossRef Medline

Velasco AL, Wilson CL, Babb TL, Engel J Jr (2000) Functional and anatomic correlates of two frequently observed temporal lobe seizure-onset patterns. Neural Plast 7:49-63. CrossRef Medline

Weinand ME, Farley C, Hussain N, Labiner DM, Ahern GL (2007) Time from ictal subdural EEG seizure onset to clinical seizure onset: an electrocorticographic time factor associated with temporal lobe epileptogenicity. Neurol Res 29:862-870. CrossRef Medline

Wennberg R, Arruda F, Quesney LF, Olivier A (2002) Preeminence of extrahippocampal structures in the generation of mesial temporal seizures: evidence from human depth electrode recordings. Epilepsia 43:716-726. CrossRef Medline

Williams PA, White AM, Clark S, Ferraro DJ, Swiercz W, Staley KJ, Dudek FE (2009) Development of spontaneous recurrent seizures after kainateinduced status epilepticus. J Neurosci 29:2103-2112. CrossRef Medline

Xing D, Yeh CI, Shapley RM (2009) Spatial spread of the local field potential and its laminar variation in visual cortex. J Neurosci 29:11540-11549. CrossRef Medline

Zangaladze A, Nei M, Liporace JD, Sperling MR (2008) Characteristics and clinical significance of subclinical seizures. Epilepsia 49:2016-2021. CrossRef Medline 